\title{
Bio-Guided Study on Melastoma malabathricum Linn Leaves and Elucidation of its Biological Activities
}

\author{
${ }^{1}$ Mourouge Saadi Alwash, ${ }^{2}$ Nazlina Ibrahim and ${ }^{2}$ Wan Yaacob Ahmad \\ ${ }^{1}$ School of Biosciences and Biotechnology, \\ ${ }^{2}$ School of Chemical Sciences and Food Technology, \\ Faculty of Science and Technology, Universiti Kebangsaan Malaysia, 43600, Bangi, Selangor, Malaysia
}

Received 2013-02-22, Revised 2013-05-14; Accepted 2013-07-04

\begin{abstract}
The present study aimed to isolate and identify constituents with antibacterial activity from the methanol extract of Melastoma malabathricum leaves (MMML) through bioassay guided fractionation. Furthermore, the study scoped to evaluate the cytotoxic effects of $M$. malabathricum leaves fractions for possible protective effect of antoxidative constituents present in the fractions. The MMML extract was fractionated by Vacuum Liquid Chromatography (VLC) to afford M. malabathricum leaves fractions (ML1-ML6) of increasing polarities. Antibacterial activity of plant extract, six fractions and two bioactive constituents against Staphylococcus aureus reference strain, methicillin-resistant Staphylococcus aureus reference strain (MRSA), eleven clinical MRSA isolates, three clinical Pseudomonas aeruginosa isolates and P. aeruginosa reference strain was evaluated using Minimum Inhibitory Concentration (MIC). The bioactive constituents responsible for antibacterial activity of MMML, fractions were detected by direct TLC-bioautography. The data obtained from MIC assay showed that ML5 effectively inhibited growth of all test bacterial pathogens. Direct TLC-bioautography revealed that ML5 had the highest number of antibacterial compounds. Following bioassay-guided fractionation, Kaempferol-3-O(2", 6"-di-O-p-trans-coumaroyl)- $\beta$-glucopyranoside and Kaempferol were isolated from ML5. The structures of bioactive compounds were elucidated using Nuclear Magnetic Resonance (NMR) spectroscopy from ${ }^{1} \mathrm{HNMR}$ and ${ }^{13} \mathrm{CNMR}$. In addition, the cytotoxic effect of M. malabathricum leaves fractions (ML1-ML6) revealed that ML5 had the highest Cytotoxicity Concentration $\left(C_{50}\right)$ at $0.75 \mathrm{mg} \mathrm{mL}^{-1}$, an observation traceable to the presence of flavonoids constituents with antioxidant properties. Therefore, the results clearly indicate that MMML, fractions and bioactive constituents have profound antibacterial activity. Furthermore, antioxidative compounds from ML5 fraction exert their effects by enhancing the level of $\mathrm{CC}_{50}$.
\end{abstract}

Keywords: Melastoma malabathricum leaves, Bioactive Constituents, Antibacterial, Antioxidant, Cytotoxic Activities

\section{INTRODUCTION}

An increasing interest in naturally derived plant products with ethno medical use in health care systems correlates with the growing utilization of their crude form in the treatment of various ailments. Plants contain diverse constituents with indispensable sources of both preventive and curative traditional medicine preparations for human beings (Sharma et al., 2010; Kalayou et al., 2012). The development of a novel drug requires the assessment of efficacy, bioavailability and safety of the drug. The widespread emergence of bacterial pathogens with the huge threat of drug resistance makes important the need to develop safe, more dependable, less costly Corresponding Author: Mourouge Saadi Alwash, School of Biosciences and Biotechnology, Faculty of Science and Technology, Universiti Kebangsaan Malaysia, 43600, Bangi, Selangor, Malaysia 
drugs with low adverse side effects and that could serve as potent alternatives to existing drugs. Thus, plants represent an unlimited source of novel chemicals entities with potential as drug leads (Brusotti et al., 2013).

In many areas, particularly in the tropics, an abundance of medicinal plants offer people access to safe and effective products for use in prevention and treatment of varying ailments (Das et al., 2010; Katovai et al., 2012). Melastoma malabathricum linn. (Melastomataceae) is one of the most important herbs or shrubs found in Malaysia and known to Malays as "senduduk". Different parts of the plant are used for the treatment of various human ailments (Zakaria et al., 2011a).

The M. malabathricum having appreciable medicinal properties that have drawn the attention of the researchers in recent times. Many pharmacological studies have been carried out including antiviral (Nazlina et al., 2008), antibacterial (Sunilson et al., 2008; Choudhury et al., 2011), antioxidant (Sirat et al., 2010) and antinociceptive, anti-inflammatory and antipyretic activities (Zakaria et al., 2011b).

For prolonged usage however, it is a desirable requirement that it should have not only antibacterial activity, but also potent antioxidant activity alongside with low cytotoxicity effects on host cells. Antioxidative compounds protect living organisms from oxidative damages caused by various Reactive Oxygen Species (ROS) such as superoxide anions $\left(\mathrm{O}_{2}^{-}\right)$, Hydroxyl radicals $(\mathrm{OH})$ and hydrogen peroxide $\left(\mathrm{H}_{2} \mathrm{O}_{2}\right)$ formed naturally by different mechanisms in the body (Verma et al., 2010). The unstable free radical molecules with unpaired electrons fleet freely through the body seeking for healthy cells to steal electrons to rebalance themselves thus causing cellular damage to components such as enzymes, protein, lipids, DNA and RNA. Most plants with ethno medical use have potent, naturally occurring antioxidant components like polyphenols and flavonoids with protective function against oxidative damage through the inhibition of free radicals and reactive oxygen (Suhartono et al., 2012). As such, natural antioxidants are in high demand in control of free radicals that cause oxidative damage.

So far there have been no attempts to study biologically active constituents with specific pharmacological activity from M. malabathricum leaves (Joffry et al., 2012). Thus, the present study was therefore scoped to isolate and identify bioactive constituents with antibacterial activity from $M$. malabathricum leaves. Furthermore, the study aimed to evaluate the cytotoxic effects of crude extract obtained via methanolic extraction, fractions obtained via Vacuum
Liquid Chromatography (VLC) and Nuclear Magnetic Resonance spectroscopy (NMR) characterized bioactive compounds obtained via column chromatography. An additional objective of the study was to identify the possible protective effect of antioxidant components of obtained fractions in preventing cellular damage associated with free radicals.

\section{MATERIALS AND METHODS}

\subsection{Plant Extraction and Isolation of Compound}

M. malabathricum Linn leaves was purchased from Ethno Herbs Resources Sdn. Bhd (Malaysia) and identified by a botanist with the specimen voucher NI01 deposited in the Herbarium, Faculty of Science and Technology, Universiti Kebangsaan Malaysia. In preliminary extraction, $50 \mathrm{~g}$ of powdered plant leaves from M. malabathricum was treated with $n$-hexane to remove fats, waxes and chlorophylls. A solvent to sample dry weight ratio of 10:1 (v/w) was used (Green, 2004). The powdered plant leaves were stirred vigorously in $\mathrm{MeOH}$ at ambient temperature for $72 \mathrm{~h}$. After $24 \mathrm{~h}$, the liquid was removed and filtered through Whatman No.1 filter paper. $\mathrm{MeOH}$ was again added to the powdered leaves. The method was repeated three times. The filtered extract was dried by rotary evaporator at $40^{\circ} \mathrm{C}$ to yield the Methanol extract of $M$. malabathricum Leaves (MMML). The MMML was fractionated by Vacuum Liquid Chromatography (VLC) on silica gel 60 (Merck, Germany; Art no.1.07747.1000) and eluted with gradient solvent system of $n$-hex: Ethyl acetate (EtOAC) $(9: 1,7: 3,5: 5,3: 7,1: 9)$ and EtOAC: $\mathrm{MeOH}(9: 1,8: 2,7: 3,6: 4,5: 5,4: 6,3: 7,2: 8$ and 1:9) and finally $\mathrm{MeOH}$. Solvents used were analytical grade (Merck, Germany). Fractions were combined based on similar profile on Thin Layer Chromatography (TLC Kieselgel 60PF254; Merck, Germany; Art no.1.05554.0001) plates to afford six M. malabathricum leaves fractions (ML1-ML6) due to difference in polarity and type of constituents extracted. Following bioassayguided fractionation, the ML5 fraction showed the highest numbers of antibacterial components with sufficient amount (2.5 g per $1 \mathrm{~kg}$ of MMML). Thus, Fraction ML5 was pre-adsorbed on silica gel and further subjected to Column Chromatography (CC) on silica gel 60 (Merck, Germany; Art no. 1.09385.1000) and eluted with the gradient solvent system of chloroform (Chl): $\mathrm{MeOH}$ to yield two bioactive target of flavonoids: Kaempferol-3-O(2",6"-di- $O$-p-trans-coumaroyl)- $\beta$-glucopyranoside and kaempferol. 


\subsection{Determination of Antibacterial Activity 2.2.1. Bacterial Strains and Growth Condition}

Staphylococcus aureus reference strain ATCC 11632, methicillin-resistant $S$. aureus reference strain ATCC 43300 (MRSA), 11 clinical MRSA isolates, Pseudomonas aeruginosa reference strain ATCC 10145 and 3 clinical $P$. aeruginosa isolates were kindly provided by the Microbiology Laboratory, School of Biosciences and Biotechnology, Faculty of Science and Technology, Universiti Kebangsaan Malaysia. The bacteria cultures were maintained in Brain Heart Infusion broth (BHIB; Oxoid, UK). Bacteria were cultured at $37^{\circ} \mathrm{C}$ for $24 \mathrm{~h}$ and then sub-cultured on BHI agar (Oxoid, UK) at $37^{\circ} \mathrm{C}$ for $24 \mathrm{~h}$. For each experiment, bacteria were re-suspended in $0.85 \%$ saline to obtain the required densities equivalent to the McFarland 0.5 turbidity standard.

\subsection{Minimum Inhibitory Concentration (MIC) Determination}

Minimum inhibitory concentrations (MICs) of MMML, the fractions (ML1-ML6) and biologically active compounds were determined according to NCCLS (2000) with two-fold serial dilutions. To each round bottom 96 -well, $100 \mu \mathrm{L}$ of standardized test bacteria $\left(10^{8}\right.$ $\mathrm{CFU} / \mathrm{mL}$ ) was added to Muller-Hinton broth (MHB; Oxoid, UK) containing various concentrations of the above samples to yield a final volume $200 \mu \mathrm{L} /$ well. A negative control was prepared using $1 \%$ DMSO while gentamicin (Sigma, France) was used as a reference antibiotic. All tests were performed in triplicates. The MIC was recorded as the lowest concentration that produced a complete suppression of visible growth after $24 \mathrm{~h}$ incubation at $37^{\circ} \mathrm{C}$.

\subsection{Minimum Bactericidal Concentration (MBC) Determination}

To determine Minimum Bactericidal Concentration (MBC), an aliquot of $5 \mu \mathrm{L}$ (from wells that exhibited no bacterial growth) was seeded onto sterile nutrient agar (NA; Oxoid, UK) and incubated overnight at $37^{\circ} \mathrm{C}$. The $\mathrm{MBC}$ was defined as the lowest concentration preventing bacterial growth.

\subsection{Direct TLC-Bioautography}

The TLC plates $(6 \times 6 \mathrm{~cm})$ were spotted with $5 \mu \mathrm{L}$ (100, 40 and $\left.20 \mathrm{mg} \mathrm{mL}^{-1}\right)$ of reconstituted MMML, the fractions (ML1-ML6) and bioactive substance and then developed with six different mobile eluting solvent systems (analytical grade) of varying polarity namely: $n$ Hexane: Chloroform (HC)(1:9); Chloroform: Acetone (CA)(1:1); Dichloromethane: Acetone (DA) (7:3); Ethyl acetate: Methanol (EM) (9.5:0.5); Benzene: Dioxane: Acetic acid (BDA) (7.8:2:0.2) and Toluene: Ethyl acetate: Formic acid (TEF) (6:3.6:0.4). Direct TLCbioautography was carried out to detect bioactive constituents by modified method of (Sgariglia et al., 2011). The plates were observed under Ultraviolet (UV) light at wavelengths of $254 \mathrm{~nm}$ and $365 \mathrm{~nm}$ (Camac Universal lamp TL-600). The eluted TLC plate 1 which served as a control was sprayed with cerium sulphate and heated for $2 \mathrm{~min}$ at $100^{\circ} \mathrm{C}$ to allow development of color whereas plate 2 was left to dry in the fume hood overnight to remove the eluent solvent system. The plate was thereafter sterilized for 20-30 min under UV light. Fully dried TLC plates were dipped for $5 \mathrm{~min}$ in the combination of MHB-MH-agar (90:10) containing $10^{8} \mathrm{CFU} / \mathrm{mL}$ of bacterial pathogens (Okusa et al., 2010). In this study, two Gram positive-bacteria including S. aureus (ATCC 11632), MRSA (ATCC 43300) one Gram-negative bacteria $P$. aeruginosa (ATCC 10145) were used. The loaded plates were placed in a humid chamber and incubated at $37^{\circ} \mathrm{C}$ overnight. Plates were then stained with $5 \mathrm{mg} \mathrm{mL}{ }^{-1}$ solution of 3-(4,5-dimethylthiazol-2-yl)-2,5diphenyltetrazolium bromide (MTT; Sigma, France) and further re-incubated at $37^{\circ} \mathrm{C}$ for $3 \mathrm{~h}$. Inhibitory zones depicted as clear areas against blue background where reduction of MTT to formazan did not occur indicated bacterial growth inhibition.

\subsection{Determination of Qualitative Antioxidant Activity of Fractions}

The qualitative antioxidant activity of $M$. malabathricum leaves fractions (ML1-ML6) was carried out using TLC (Deby and Margotteaux, 1970). TLC plates $(6 \times 6 \mathrm{~cm})$ were prepared as described above. Bioactive constituents were separated and then sprayed with $0.2 \%$ 1, 1-diphenyl-2-picrylhydrazyl in $\mathrm{MeOH}$ (DPPH; Sigma, France). A positive reaction was observed as yellow spots against a purple background.

\subsection{Determination of the Cytotoxic Activity of MMML, Fractions and Isolated Compounds}

Cytotoxicity assay was performed according to Raheel et al. (2013) against Vero cells (African green monkey kidney cells). The cells were maintained in Dulbecco's Modified Eagle's Medium (DMEM) supplemented with 5\% Fetal Bovine Serum (FBS). 
Cultures for the assay were prepared from confluent monolayer cells, seeded at a density of $2 \times 10^{4}$ cells/well in 96-well microplates flat bottom and incubated at $37^{\circ} \mathrm{C}$ overnight in a $5 \% \mathrm{CO}_{2}$ to allow attachment of the cells. The growth media on confluent Vero cells grown overnight was removed and replaced with $100 \mu \mathrm{L}$ (100, 40 and $20 \mathrm{mg} \mathrm{mL}^{-1}$ ) of respective MMML, $M$. malabathricum leaves fractions (ML1-ML6) and isolated compounds. It was followed by reconstitution in $5 \%$ dimethyl sulfoxide (DMSO) and preparation in growth media at various concentrations. DMEM supplemented with 5\% DMSO was used as negative control and Berberine chloride (Sigma, France) was used as positive control. After incubation at $37^{\circ} \mathrm{C}$ in a $5 \% \mathrm{CO}_{2}$ for $48 \mathrm{~h}$, the viability of cells was determined by MTT assay based on the reductive cleavage of the 3-(4,5-dithiazol-2yl)-2,5-diphenyltetrazolium bromide, a yellow tetrazole (MTT, Sigma, France), by mitochondrial dehydrogenase enzyme present in living cells to yield purple formazan crystals. The media on the cells was removed, $100 \mu \mathrm{L}$ of DMEM and $20 \mu \mathrm{L}$ of $5 \mathrm{mg} \mathrm{mL}^{-1}$ MTT dissolved in Phosphate Buffer Solution (PBS) were added to each well. The plates were re-incubated for $4 \mathrm{~h}$ under the same conditions. After incubation, MTT was removed and 100 $\mu \mathrm{L}$ of DMSO was added to each well. Subsequently, the plates were gently rocked to dissolve the formazan crystals. The Optical Density (OD) of each well was measured at wavelength of $540 \mathrm{~nm}$ by an ELISA reader (CDS, India). Cytotoxicity was expressed as 50\% Cytotoxic Concentration $\left(\mathrm{CC}_{50}\right)$ of constituents that inhibit the growth of cells by $50 \%$ when compared to untreated cells. The percentage of cell viability was measured as follows:

Viability $=\frac{(\text { Treated cells }- \text { Blank })}{(\text { Untreated cells }- \text { Blank })} \times 100$

For the purpose of measuring selectivity index (SI), selective index of crude extract, six fractions and isolated compounds were calculated as follows:

Selectivity index $(\mathrm{SI})=\frac{\mathrm{CC}_{50}}{\mathrm{MIC}}$

\section{RESULTS}

\subsection{Isolation of Biological Active Compounds}

The chromatographic separation of MMML by VLC afforded six M. malabathricum leaves fractions (ML1-
ML6). Following bioassay-guided fractionation, direct TLC-bioautography revealed the presence of bioactive constituents responsible for antibacterial activity using $S$. aureus and MRSA. Purification of the ML5 by column chromatography (CC) resulted in the isolation of Kaempferol-3-O-(2",6"-di-O-p-trans-coumaroyl)- $\beta$ glucopyranoside (1) and Kaempferol (2) Fig. 1 The structures of the compounds were elucidated using data obtained from ${ }^{1} \mathrm{H}$ and ${ }^{13} \mathrm{C}$ NMR spectra.

\subsection{Antibacterial Activity of Extract, Fractions and Isolated Compounds}

3.2.1. Minimum Inhibitory Concentration (MIC)

The antibacterial activity of MMML, $M$. malabathricum leaves fractions (ML1-ML6) and bioactive compounds against $S$. aureus reference strain, MRSA reference strain and 11 clinical MRSA isolates, $P$. aeruginosa reference strain and 3 clinical $P$. aeruginosa isolates is shown in Table $\mathbf{1}$ as MIC and MBC values. In the present study, MMML exhibited antibacterial activity with the MIC values between $0.78 \pm 0$ and $3.13 \pm 0 \mathrm{mg} \mathrm{mL}^{-1}$ against all tested pathogenic bacteria. Differences in antibacterial activity were observed with varying polarity of fractions. The data obtained from MIC values showed that $M$. malabathricum leaves fractions (ML1-ML6) effectively inhibited the growth of tested pathogenic bacteria, the antibacterial activity of ML5 being much greater than other fractions. In general, ML5 exhibited the highest antibacterial activity with MIC values between $0.125 \pm 0$ and $0.25 \pm 0 \mathrm{mg} \mathrm{mL}^{-1}$ against $S$. aureus and MRSA while the MIC values were found to be between $0.5 \pm 0$ and $1 \pm 0$ $\mathrm{mg} \mathrm{mL} \mathrm{m}^{-1}$ against $P$. aeruginosa reference strain and 3 clinical $P$. aeruginosa isolates. Following bioassayguided fractionation, ML5 afforded two flavonoids that were evaluated for their antibacterial activity against tested pathogenic bacteria. The antibacterial activity of bioactive compounds is presented in Table 1. For compound (2), the MIC values varied between $0.25 \pm 0$ and $0.5 \pm 0 \mathrm{mg} \mathrm{mL}^{-1}$ against $S$. aureus, MRSA reference strain and 11 clinical MRSA isolates whereas it showed low antibacterial activity against all tested $P$. aeruginosa isolates with MIC values between $1 \pm 0$ and $4 \pm 0 \mathrm{mg} \mathrm{mL}^{-1}$. Compound (1) was more active than (2) against all tested bacteria with MIC values ranging from $0.125 \pm 0$ to $0.25 \pm 0 \mathrm{mg} \mathrm{mL} \mathrm{m}^{-1}$ against $S$. aureus and MRSA while MIC values between $0.5 \pm 0$ and $1 \pm 0 \mathrm{mg} \mathrm{mL}^{-1}$ was recorded when tested against $P$. aeruginosa. 


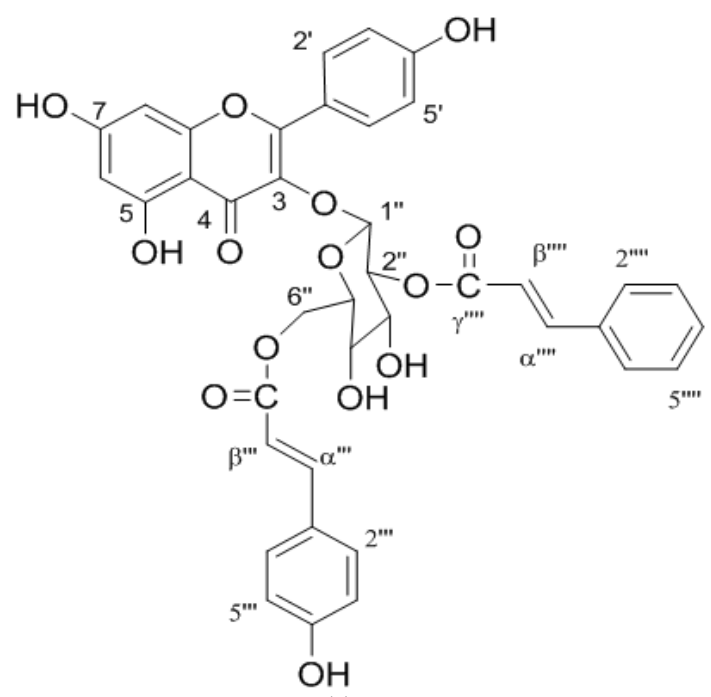

(a)<smiles>[O]c1cc(O)c2c(=O)c(O)c(-c3ccc(O)cc3)oc2c1</smiles>

(b)

Fig. 1. Structure of compounds isolated from M. malabathricum Linn leaves Compound (a): Kaempferol-3-O-(2,“6”-di-O-trans-pcoumaroyl)- $\beta$-D-glucopyranoside Compound (b): Kaempferol

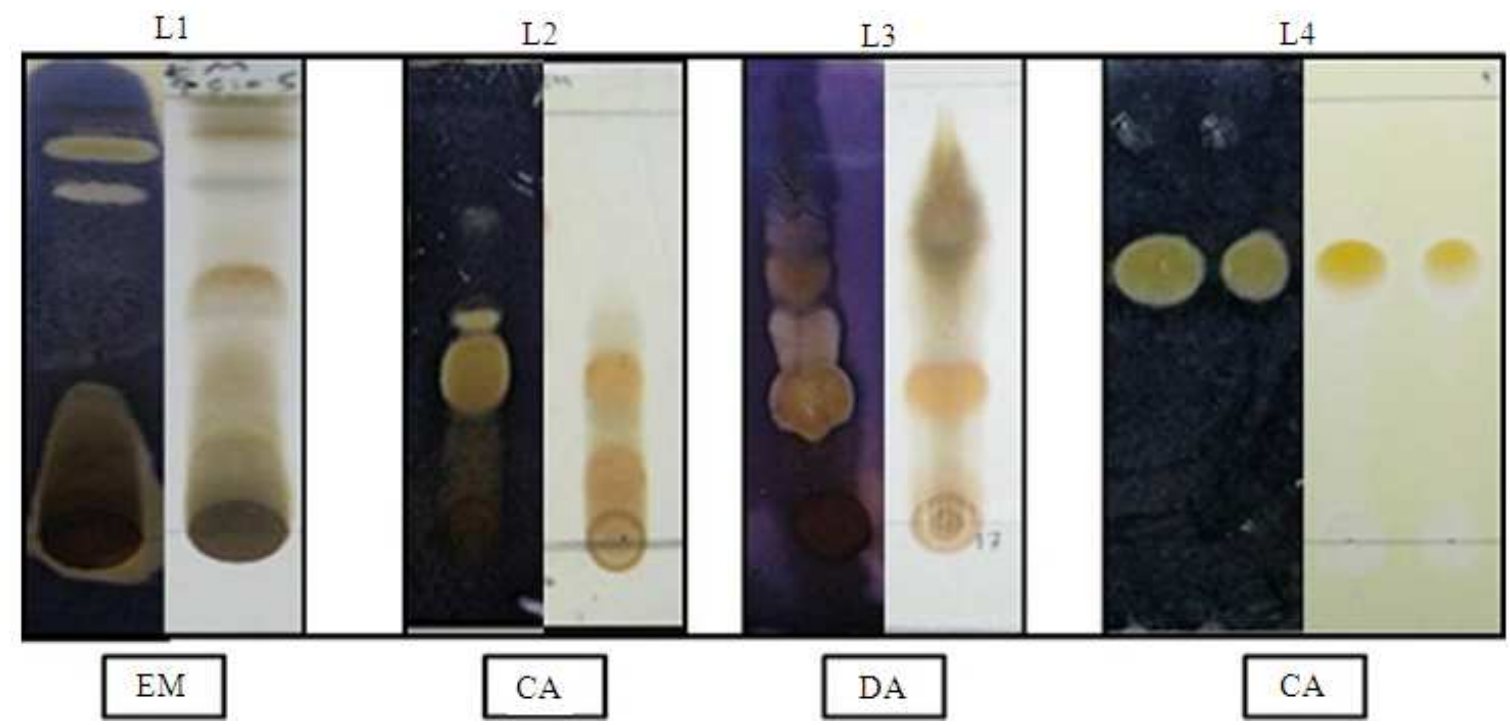

Fig. 2. Thin layer bioautographs of M. malabathricum leaves developed with various eluent systems. In each set, the left chromatogram was loaded with the bacteria MRSA and the one to the right without bacteria. The lanes from left to right were: L1: Methanol extract of M. malabathricum leaves (MMML), L2 and 3: M. malabathricum leaves fraction of ML5 and L4: Comp.1: Kaempferol-3-O-(2,“6”-di-O-trans-p-coumaroyl)- $\beta$-D-glucopyranoside, EM: Ethyl acetate-methanol, DA: Dichloromethane-acetone, CA: Chloroform-acetone

Inhibition of Bacterial Growth indicated by Direct TLCBioautography: Direct TLC-bioautography was used to screen the presence of varied bioactive components in MMML and its fractions. The appearance of clear areas against blue background on the TLC plates where reduction to formazan didn't occur after using MTT reflects inhibition of bacterial growth as was obtained for MMML, ML5 and compound (1) (Fig. 2). 

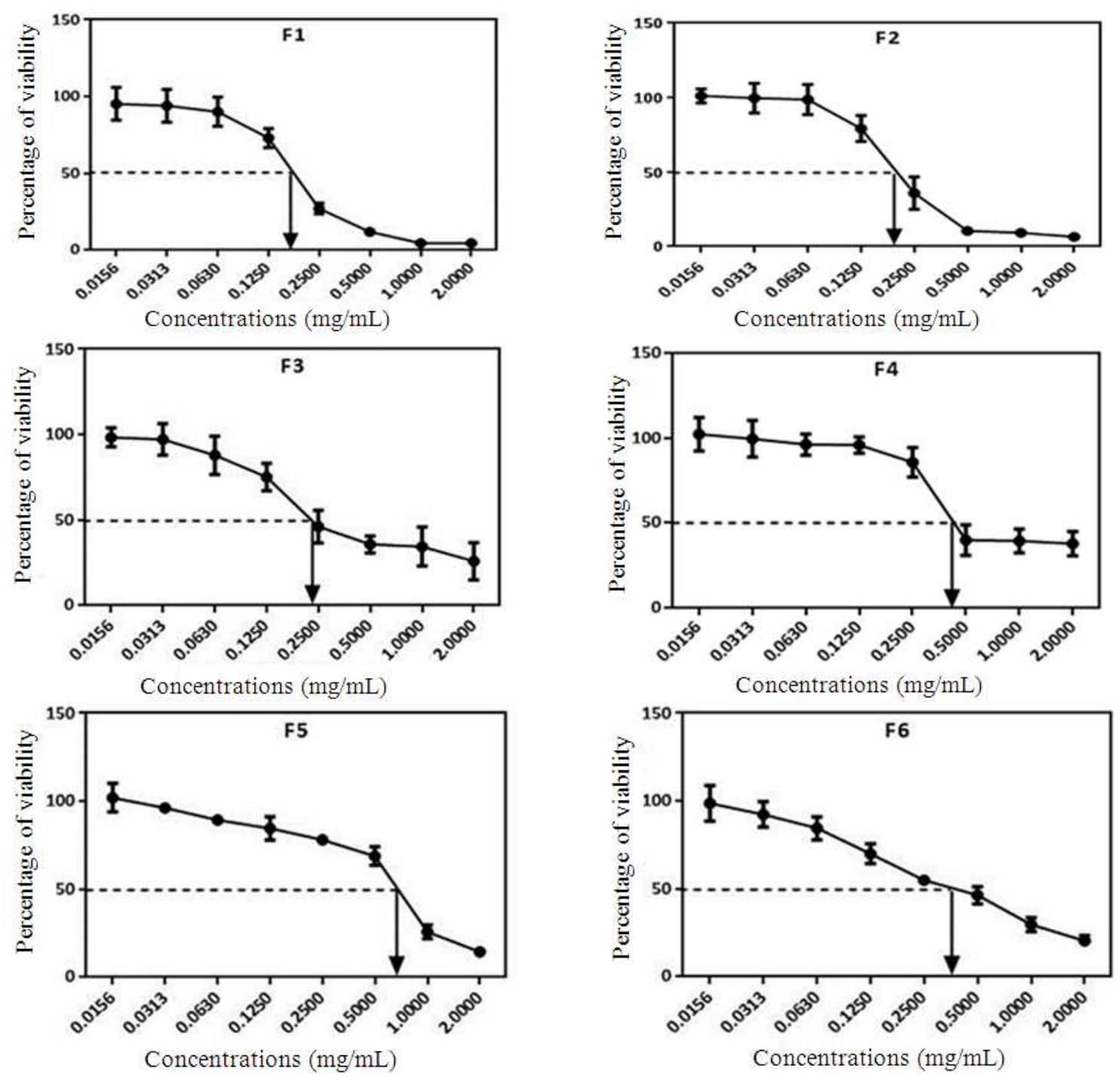

Fig. 3. Effect of six fractions on the growth of the Vero cells line showing percentage viability of cells by MTT assay (ML1-ML6): M. malabathricum leaves fractions

An important factor in quantifying the movement of compounds on a stationary phase using mobile eluting solvent system is the retention factor $\left(\mathrm{R}_{\mathrm{f}}\right)$ that represents the ratio of the distance moved by the compound from its origin to the movement of the solvent from the origin. The $\mathrm{R}_{\mathrm{f}}$ values of bioactive compounds against $S$. aureus, MRSA in MMML, ML5 and compound (1) eluted with various solvent systems are presented in Table 3. In MMML, the $\mathrm{R}_{\mathrm{f}}$ values of compounds active against $S$. aureus and MRSA in EA were 0.89, 0.78, 0.29 and 0.18. Considering a reflection of the difference in polarity of the solvent systems used, the $\mathrm{R}_{\mathrm{f}}$ values of ML5 against $S$. aureus and MRSA developed in (CA) were $0.33,0.4$ and 0.76 while for (DA), they were $0.27,0.38$ and 0.47 . On the other hand, the $\mathrm{R}_{\mathrm{f}}$ value for bioactive compound (1) against $S$. aureus and MRSA in CA was 0.62.

\subsection{Determination of Cytotoxic Effect of Fractions}

The cytotoxic effect of six M. malabathricum leaves fractions at concentrations ranging from 0.0156 to $2 \mathrm{mg}$ $\mathrm{mL}^{-1}$ were tested on Vero cells using the MTT assay which is based on the ability of mitochondrial dehydrogenase enzyme from living cells to cleave tetrazolium rings of the MTT to form dark blue formazan crystals. 


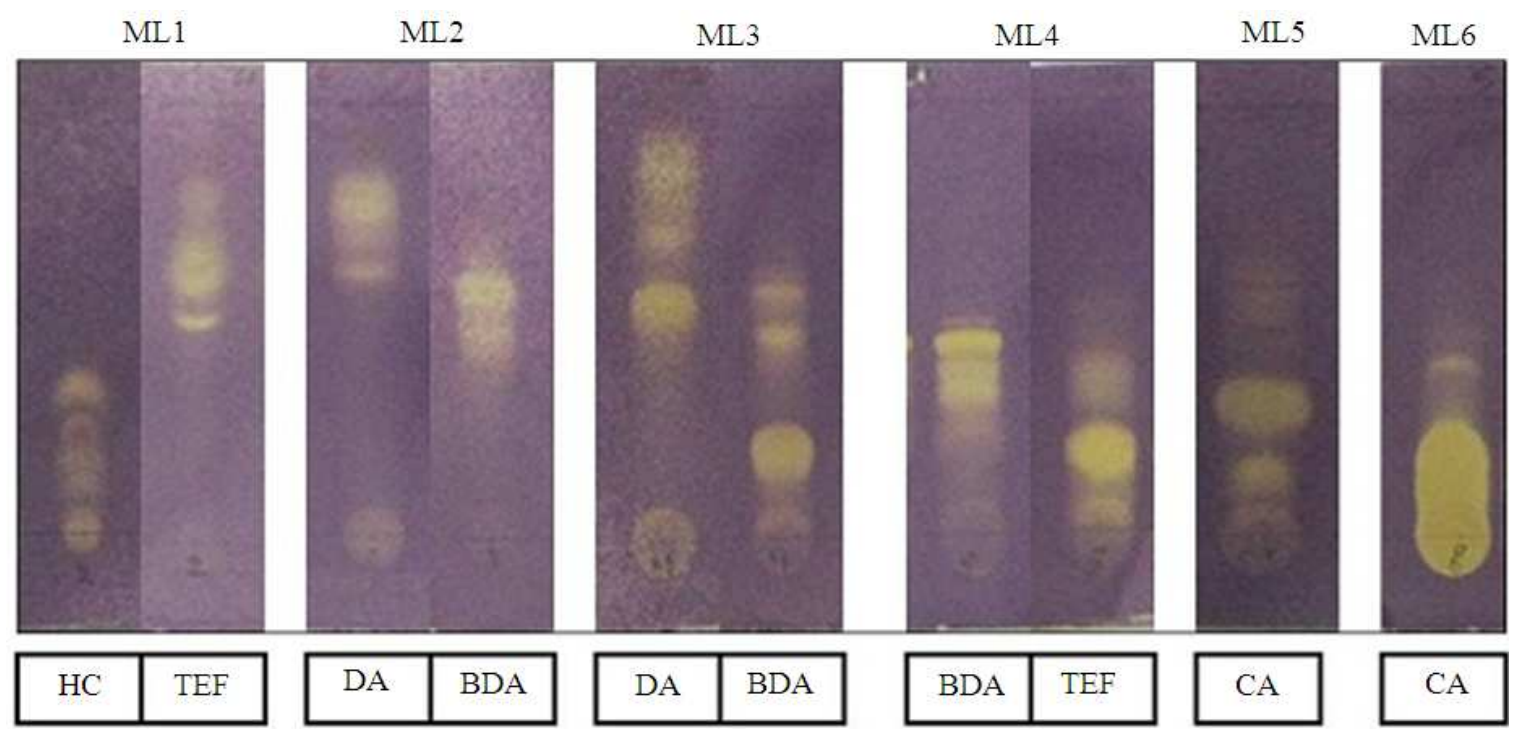

Fig. 4. TLC developed in different solvent systems indicating presence of antioxidative constituents in fractions, (ML1-ML6): $M$. malabathricum leaves fractions, HC: Hexane-Chloroform, DA: Dichloromethane-Acetone, BDA: Benzene-Dioxane-Acetic acid, CA: Chloroform-Acetone and TEF: Toluene-Ethyl acetate-Formic acid

The Berberine chloride standard was also determined at the same concentrations and gave $\mathrm{CC}_{50}$ value of $3.0 \mu \mathrm{g}$ $\mathrm{mL}^{-1}$. Percent Vero cells viability based on MTT assay following exposure to the six fractions of MMML is presented in Fig. 3. Error bars indicate standard deviation values are present on all graphs. At the highest concentration $2 \mathrm{mg} \mathrm{mL}$, fractions (ML1-ML6) of MMML exhibited deleterious effects on the viability of Vero cells. However, at concentrations below $0.063 \mathrm{mg}$ $\mathrm{mL}^{-1}$, Vero cells were more tolerant to the toxic effect within cells viability between 70 and $90 \%$ in all fractions according to Fig. 3.

\subsection{Antioxidant Activity}

To detect the presence of compounds with a potent antioxidant activity, six $M$. malabathricum leaves fractions (ML1-ML6) were screened for the presence of antioxidant substances. Fig. 4 represents chromatograms of thin layer chromatography with six fractions developed with different eluent solvent systems and sprayed with $0.2 \%$ DPPH solution in methanol. Antioxidant compounds were depicted as yellow spots against purple background.

\section{DISCUSSION}

Antibiotic drug resistance is increasing worldwide in both hospitalized patients and outpatients. It is directly proportional to the use and misuse of antibiotics. Even though newer antibiotic, continued selective antibiotic pressure and bacterial adaptation have resulted in a problem that can no longer be ignored. Thus, the prevalence of antibiotic-resistant bacteria has increased and multi-drug-resistant strains have emerged in many species that cause human disease. $S$. aureus, MRSA and $P$. aeruginosa have been recognized as the most important bacteria that cause diseases in humans (Orhan et al., 2010). The Antibacterial activity of M. malabathricum has been documented (Sunilson et al., 2008; Choudhury et al., 2011). Antibacterial activity of M. malabathricum was evaluated against standard and clinical isolates of Grampositive and Gram-negative pathogenic bacteria (Table 1). A bio-guided study of ML5 resulted in isolation of two flavonoids. In review of Joffry et al. (2012), it was stated that $M$. malabathricum leaves contains phytochemical constituents and are strongly associated with ethno medicinal values such as flavonoids, triterpenes, tannins, saponins and steroids. Flavonoids are classified under phenolic groups in plants and have been known to possess antimicrobial activity. The antibacterial activity of flavonoids from plants with a history of use in folk medicine has been documented (Dulger and Hacioglu, 2009; Marzouk et al., 2010). Many factors have been reported to be responsible for antibacterial activity of flavonoids. 
Mourouge Saadi Alwash et al. / American Journal of Applied Sciences 10 (8): 767-778, 2013

\begin{tabular}{|c|c|c|c|c|c|c|c|c|c|c|c|c|c|c|c|c|c|c|}
\hline \multirow[b]{4}{*}{ Test bacteria } & \multicolumn{18}{|c|}{ Plant extract/ fraction/compound } \\
\hline & \multicolumn{18}{|c|}{ Susceptibility of bacteria $(\mathrm{mg} / \mathrm{m} \mathrm{L})$} \\
\hline & \multicolumn{2}{|c|}{ MMML } & \multicolumn{2}{|c|}{ ML1 (NS) } & \multicolumn{2}{|c|}{ ML2 (NS) } & \multicolumn{2}{|l|}{ ML3 } & \multicolumn{2}{|l|}{ ML4 } & \multicolumn{2}{|l|}{ ML5 } & \multicolumn{2}{|l|}{ ML6 } & \multicolumn{2}{|l|}{ Comp.1 } & \multicolumn{2}{|l|}{ Comp.2 } \\
\hline & MIC & MBC & MIC & $\mathrm{MBC}$ & MIC & $\mathrm{MBC}$ & MIC & $\mathrm{MBC}$ & MIC & $\mathrm{MBC}$ & MIC & $\mathrm{MBC}$ & MIC & $\mathrm{MBC}$ & MIC & MBC & MIC & $\mathrm{BC}$ \\
\hline \multicolumn{19}{|l|}{ Gram-positive } \\
\hline $\begin{array}{l}\text { S. aureus } \\
\text { ATCC } 11632\end{array}$ & $1.56 \pm 0$ & $3.13 \pm 0$ & $0.25 \pm 0$ & $0.5 \pm 0$ & $0.25 \pm 0$ & $0.5 \pm 0$ & $0.25 \pm 0$ & $0.5 \pm 0$ & $0.5 \pm 0$ & $1 \pm 0$ & $0.25 \pm 0$ & $0.2 \pm 0$ & $0.5 \pm 0$ & $1 \pm 0$ & $0.25 \pm 0$ & $0.5 \pm 0$ & $0.5 \pm 0$ & $1 \pm 0$ \\
\hline $\begin{array}{l}\text { MRSA } \\
\text { ATCC } 43300\end{array}$ & $1.56 \pm 0$ & $3.13 \pm 0$ & $0.25 \pm 0$ & $0.5 \pm 0$ & $0.25 \pm 0$ & $0.5 \pm 0$ & $0.25 \pm 0$ & $0.5 \pm 0$ & $0.5 \pm 0$ & $1 \pm 0$ & $0.25 \pm 0$ & $0.2 \pm 0$ & $0.5 \pm 0$ & $1 \pm 0$ & $0.25 \pm 0$ & $0.5 \pm 0$ & $0.5 \pm 0$ & $1 \pm 0$ \\
\hline \multicolumn{19}{|l|}{ Clinical MRSA } \\
\hline M 01 & $0.78 \pm 0$ & $1.56 \pm 0$ & $0.125 \pm 0$ & $0.25 \pm 0$ & $0.125 \pm 0$ & $0.25 \pm 0$ & $0.125 \pm 0$ & $0.25 \pm 0$ & $0.25 \pm 0$ & $0.5 \pm 0$ & $0.125 \pm 0$ & $0.25 \pm 0$ & $0.25 \pm 0$ & $0.5 \pm 0$ & $0.125 \pm 0$ & $0.25 \pm 0$ & $0.25 \pm 0$ & $0.5 \pm 0$ \\
\hline M 02 & $0.78 \pm 0$ & $1.56 \pm 0$ & $0.125 \pm 0$ & $0.25 \pm 0$ & $0.125 \pm 0$ & $0.25 \pm 0$ & $0.125 \pm 0$ & $0.25 \pm 0$ & $0.25 \pm 0$ & $0.5 \pm 0$ & $0.125 \pm 0$ & $0.25 \pm 0$ & $0.25 \pm 0$ & $0.5 \pm 0$ & $0.125 \pm 0$ & $0.25 \pm 0$ & $0.25 \pm 0$ & $0.5 \pm 0$ \\
\hline M 03 & $0.78 \pm 0$ & $1.56 \pm 0$ & $0.125 \pm 0$ & $0.25 \pm 0$ & $0.125 \pm 0$ & $0.25 \pm 0$ & $0.25 \pm 0$ & $0.5 \pm 0$ & $0.25 \pm 0$ & $0.5 \pm 0$ & $0.125 \pm 0$ & $0.25 \pm 0$ & $0.25 \pm 0$ & $0.5 \pm 0$ & $0.125 \pm 0$ & $0.25 \pm 0$ & $0.25 \pm 0$ & $0.5 \pm 0$ \\
\hline M 04 & $0.78 \pm 0$ & $1.56 \pm 0$ & $0.125 \pm 0$ & $0.25 \pm 0$ & $0.125 \pm 0$ & $0.25 \pm 0$ & $0.25 \pm 0$ & $0.5 \pm 0$ & $0.25 \pm 0$ & $0.5 \pm 0$ & $0.125 \pm 0$ & $0.25 \pm 0$ & $0.25 \pm 0$ & $0.5 \pm 0$ & $0.125 \pm 0$ & $0.25 \pm 0$ & $0.25 \pm 0$ & $0.5 \pm 0$ \\
\hline M 05 & $0.78 \pm 0$ & $1.56 \pm 0$ & $0.125 \pm 0$ & $0.25 \pm 0$ & $0.125 \pm 0$ & $0.25 \pm 0$ & $01.25 \pm 0$ & $0.25 \pm 0$ & $0.25 \pm 0$ & $0.5 \pm 0$ & $0.125 \pm 0$ & $0.25 \pm 0$ & $0.25 \pm 0$ & $0.5 \pm 0$ & $0.125 \pm 0$ & $0.25 \pm 0$ & $0.25 \pm 0$ & $0.5 \pm 0$ \\
\hline M 06 & $1.56 \pm 0$ & $3.13 \pm 0$ & $0.25 \pm 0$ & $0.5 \pm 0$ & $0.25 \pm 0$ & $0.5 \pm 0$ & $0.25 \pm 0$ & $0.5 \pm 0$ & $0.5 \pm 0$ & $1 \pm 0$ & $0.25 \pm 0$ & $0.5 \pm 0$ & $0.5 \pm 0$ & $1 \pm 0$ & $0.25 \pm 0$ & $0.5 \pm 0$ & $0.5 \pm 0$ & $1 \pm 0$ \\
\hline M 07 & $0.78 \pm 0$ & $1.56 \pm 0$ & $0.25 \pm 0$ & $0.5 \pm 0$ & $0.125 \pm 0$ & $0.25 \pm 0$ & $0.25 \pm$ & $0.5 \pm 0$ & $0.25 \pm 0$ & $0.5 \pm 0$ & $0.125 \pm 0$ & $0.25 \pm 0$ & $0.5 \pm 0$ & $1 \pm 0$ & $0.25 \pm 0$ & $0.5 \pm 0$ & $0.5 \pm 0$ & $1 \pm 0$ \\
\hline M 08 & $0.78 \pm 0$ & $1.56 \pm 0$ & $0.25 \pm 0$ & $0.5 \pm 0$ & $0.125 \pm 0$ & $0.25 \pm$ & $0.125 \pm 0$ & $0.25 \pm 0$ & $0.5 \pm 0$ & $1 \pm 0$ & $0.125 \pm 0$ & $0.25 \pm 0$ & $0.25 \pm$ & $0.5 \pm 0$ & $0.125 \pm$ & $0.25 \pm 0$ & $0.25 \pm 0$ & $0.5 \pm 0$ \\
\hline M 09 & $1.56 \pm 0$ & $3.13 \pm 0$ & $0.25 \pm 0$ & $0.5 \pm 0$ & $0.25 \pm 0$ & $0.5 \pm 0$ & $0.25 \pm 0$ & $0.5 \pm 0$ & $0.5 \pm 0$ & $1 \pm 0$ & $0.25 \pm 0$ & $0.5 \pm 0$ & $0.5 \pm 0$ & $1 \pm 0$ & $0.25 \pm$ & $0.5 \pm 0$ & $0.5 \pm 0$ & $1 \pm 0$ \\
\hline M 10 & $0.78 \pm 0$ & $1.56 \pm 0$ & $0.123 \pm 0$ & $0.25 \pm 0$ & $0.125 \pm 0$ & $0.25 \pm$ & $0.25 \pm$ & $0.5 \pm 0$ & $0.5 \pm 0$ & $1 \pm 0$ & $0.125 \pm 0$ & $0.25 \pm 0$ & $0.25 \pm 0$ & $0.5 \pm 0$ & $0.25 \pm 0$ & $0.5 \pm 0$ & $0.5 \pm 0$ & $1 \pm 0$ \\
\hline $\begin{array}{l}\text { P. aeruginosa } \\
\text { ATCC } 10145\end{array}$ & $1.56 \pm 0$ & $3.13 \pm 0$ & $1 \pm 0$ & $2 \pm 0$ & $1 \pm 0$ & $2 \pm 0$ & $1 \pm 0$ & $2 \pm 0$ & $1 \pm 0$ & $2 \pm 0$ & $0.5 \pm 0$ & $1 \pm 0$ & $1 \pm 0$ & $2 \pm 0$ & $0.5 \pm 0$ & $1 \pm 0$ & $2 \pm 0$ & $4 \pm 0$ \\
\hline \multicolumn{19}{|c|}{ Clinical P. acruginosea } \\
\hline P 01 & $0.78 \pm 0$ & $1.56 \pm 0$ & $0.5 \pm 0$ & $1 \pm 0$ & $1 \pm 0$ & $2 \pm 0$ & $1 \pm 0$ & $2 \pm 0$ & $1 \pm 0$ & $2 \pm 0$ & $0.5 \pm 0$ & $1 \pm 0$ & $1 \pm 0$ & $2 \pm 0$ & $0.5 \pm 0$ & $1 \pm 0$ & $1 \pm 0$ & $2 \pm 0$ \\
\hline P 02 & $3.13 \pm 0$ & $6.25 \pm 0$ & $2 \pm 0$ & $4 \pm 0$ & $2 \pm 0$ & $4 \pm 0$ & $2 \pm 0$ & $4 \pm 0$ & $2 \pm 0$ & $4 \pm 0$ & $1 \pm 0$ & $2 \pm 0$ & $2 \pm 0$ & $4 \pm 0$ & $1 \pm 0$ & $2 \pm 0$ & $4 \pm 0$ & $8 \pm 0$ \\
\hline P 03 & $1.56 \pm 0$ & $3.13 \pm 0$ & $1 \pm 0$ & $2 \pm 0$ & $1 \pm 0$ & $2 \pm 0$ & $1 \pm 0$ & $2 \pm 0$ & $1 \pm 0$ & $2 \pm 0$ & $0.5 \pm 0$ & $1 \pm 0$ & $1 \pm 0$ & $2 \pm 0$ & $0.5 \pm 0$ & $1 \pm 0$ & $2 \pm 0$ & $4 \pm 0$ \\
\hline
\end{tabular}

MMML: Methanol extract of M. malabathricum leaves, (ML1-ML6): M. malabathricum leaves fractions

Comp.1: Kaempferol-3-O-(2",6"-di-O-trans-p-coumaroyl)- $\beta$-D-glucopyranosidea

Comp.2: Kaempferol, NS: Not sufficient amount

Table 2. Selectivity Index values (SI) of MMML, fractions (ML1-ML6) and bioactive constituents relating to antibacterial activity (MIC in $\mathrm{mg} / \mathrm{mL}$ ) against $S$. aureus ATCC 11632, MRSA ATCC 43300 and P. aeruginosa ATCC 10145, with cytotoxic concentration $\left(\mathrm{CC}_{50}\right)$

\begin{tabular}{|c|c|c|c|c|c|c|c|}
\hline \multirow{2}{*}{$\begin{array}{l}\text { MMML/fractions/ } \\
\text { Bioactive compounds }\end{array}$} & \multicolumn{3}{|c|}{$\mathrm{MIC}(\mathrm{mg} / \mathrm{mL})$} & \multirow{2}{*}{$\begin{array}{l}\mathrm{CC}_{50} \\
(\mathrm{mg} / \mathrm{mL})\end{array}$} & \multicolumn{3}{|l|}{ SI } \\
\hline & S. aureus & MRSA & P. aeruginosa & & S. aureus & MRSA & P. aeruginoss \\
\hline$\overline{\mathrm{MMML}}$ & 1.5600 & 1.5600 & 1.5600 & 3.750 & 2.400 & 2.400 & 2.400 \\
\hline ML1 & 0.5000 & 0.2500 & 0.5000 & 0.188 & 0.376 & 0.752 & 0.375 \\
\hline ML2 & 0.5000 & 0.2500 & 0.5000 & 0.188 & 0.376 & 0.752 & 0.376 \\
\hline ML3 & 1.0000 & 0.2500 & 1.0000 & 0.219 & 0.219 & 0.876 & 0.219 \\
\hline ML4 & 0.5000 & 0.5000 & 0.5000 & 0.438 & 0.876 & 0.876 & 0.876 \\
\hline ML5 & 0.2500 & 0.1250 & 0.5000 & 0.750 & 3.000 & 6.000 & 1.500 \\
\hline ML6 & 0.2500 & 0.2500 & 0.5000 & 0.375 & 1.500 & 1.500 & 0.750 \\
\hline Comp.1 & 0.2500 & 0.2500 & 0.5000 & 0.750 & 3.000 & 3.000 & 1.500 \\
\hline Comp. 2 & 0.5000 & 0.5000 & 1.0000 & 0.750 & 1.500 & 1.500 & 0.750 \\
\hline Gentamicin & 0.0004 & 0.0004 & 0.0064 & & & & \\
\hline
\end{tabular}

MIC: Minimum Inhibitory Concentration, $\mathrm{CC}_{50}$ : Cytoxic Concentration, MMML: Methanol extract of M. malabathricum leaves, ML1-ML6: M. malabathricum leaves fractions

Comp.1: Kaempferol-3-O-(2, “6”-di-O-trans-p-coumaroyl)- $\beta$-D-glucopyranoside

Comp.2: Kaempferol, NS: not sufficient amount

The presence of hydroxyl group at position 4 ' in the B ring, 5,7-dihydroxyl substitutions in the $\mathrm{A}$ ring improve the antibacterial activity that supports the earlier findings of Otsuka et al. (2008) who confirmed that hydroxylation at this position enhances antibacterial activity of flavanoids against MRSA. On the other hand, a possible explanation that the most antibacterial activity against all test pathogens may be evident in the presence of an $O$-acyl or $O$-alkyl chain at position 3 of the ring $\mathrm{C}$, a functional group that enhances activity of flavonols (Cushnie and Lamb, 2011). 
Gautam et al. (2012) reported that the antimicrobial activity of phenolic groups including flavonoids involves the alteration of the permeability of the cell membrane that could result in the uncoupling of oxidative phosphorylation, active transport inhibition and loss of pool metabolites as a result of cytoplasmic membrane damage. As well as, the presence of hydroxyl group in phenolic compound might affect their antimicrobial effectiveness by binding to the active site of enzymes, from hydrogen bonds with enzymes and alter their metabolism and also the lipid solubility and the degree of the steric hindrance of the phenolic substances might also determine their antimicrobial property.

A comparison in susceptibility of the bacterial strains to the fractions indicated that the strongest inhibitory effect was against Gram-positive bacteria. A variation in sensitivity between Gram-positive and Gram-negative bacteria was obtained with various fractions (Table 1). Recent findings showed that Gram- positive bacteria are more sensitive to antibacterial compounds than Gram-negative bacteria. Differences in the degree of susceptibility can be attributed to the porous nature of the outer peptidoglycan layer of the cell wall of Gram-positive bacteria which are more permeable to antibacterial substances than that of Gramnegative bacteria. On the other hand, Gram-negative bacteria have an outer phospholipidic membrane carrying the structural lipopolysaccharide substances that make the cell wall impermeable to lipophilic solutes (Nostro et al., 2000).

Selectivity index calculated using the $\mathrm{CC}_{50}$ and MIC values indicated highest selectivity index for ML5 fraction against MRSA followed by $S$. aureus and $P$. aeruginosa (Table 2). Overall, in terms of MIC values, ML5 fraction had acceptable antibacterial activity with highest selectivity index value followed by compound (1).

Table 3. Retention factor values $\left(\mathrm{R}_{\mathrm{f}}\right)$ of bioactive constituents representing bacterial growth inhibition on bioautograms

\begin{tabular}{|c|c|c|c|c|}
\hline & \multicolumn{4}{|c|}{ Eluent solvent systems } \\
\hline & MMML & ML5 & & Comp 1 \\
\hline & EM & $\mathrm{CA}$ & DA & $\mathrm{CA}$ \\
\hline \multirow[t]{4}{*}{ S. aureus } & 0.89 & 0.33 & 0.27 & 0.62 \\
\hline & 0.78 & 0.40 & 0.38 & \\
\hline & 0.29 & 0.76 & 0.47 & \\
\hline & 0.18 & & & \\
\hline \multirow[t]{4}{*}{ MRSA } & 0.89 & 0.27 & 0.33 & 0.62 \\
\hline & 0.78 & 0.38 & 0.44 & \\
\hline & 0.29 & 0.47 & 0.76 & \\
\hline & 0.18 & & & \\
\hline Total active bands & 4.00 & 3.00 & 3.00 & 1.00 \\
\hline
\end{tabular}

MMML: Methanol extract of M. malabathricum leaves,

ML5: M. malabathricum leaves fraction 5

Compound.1: Kaempferol-3-O-(2",6"-di-O-trans-p-coumaroyl)- $\beta$-D-glucopyranoside

EM: Ethyl acetate-Methanol, DA: Dichloromethane-Acetone, CA: Chloroform-Acetone

Table 4. Retention factor $\left(\mathrm{R}_{\mathrm{f}}\right)$ values of antioxidative compounds in fractions

\begin{tabular}{|c|c|c|c|c|c|c|c|c|c|c|}
\hline & M. $M$ & thricu & & & & & & & & \\
\hline & ML1 & & ML2 & & ML3 & & ML4 & & & \\
\hline & $\mathrm{HC}$ & TEF & DA & BDA & DA & BDA & BDA & TEF & CA & $\mathrm{CA}$ \\
\hline & 0.11 & 0.44 & 0.6 & 0.42 & 0.51 & 0.16 & 0.29 & 0.13 & 0.33 & 0.18 \\
\hline & 0.16 & 0.51 & 0.71 & 0.56 & 0.73 & 0.51 & 0.36 & 0.18 & 0.4 & 0.31 \\
\hline & 0.22 & 0.58 & & & 0.84 & 0.6 & 0.44 & 0.31 & & \\
\hline & 0.27 & 0.67 & & & & & & & & \\
\hline Total & 4.00 & 4.00 & 2.00 & 2.00 & 3.00 & 3.00 & 3.00 & 3.00 & 2.00 & 2.00 \\
\hline
\end{tabular}

ML1-ML6: M. malabathricum leaves fractions, HC: Hexane-Chloroform, DA: Dichloromethane-Acetone, BDA: Benzene-DioxaneAcetic acid, CA: Chloroform-Acetone and TEF: Toluene-Ethyl acetate-Formic acid 
Though, direct TLC-bioautography is not a quantitative method to determine antimicrobial activity, it is still a very useful method in indicating and isolating compounds with antimicrobial activity (Suleiman et al., 2010). Comparing the presence of bioactive constituents, variation was found between susceptibility of tested bacteria. Even though, MIC values exerted good antibacterial activity in ML5, no inhibition of bacterial growth was observed making it difficult to determine inhibitory zones particularly in $P$. aeruginosa. The absence of activity could be attributed to photooxidation, evaporation of the active compounds or to very little amount of the bioactive components (Masoko and Eloff, 2005). It is also possible that the poor growth of pathogenic bacteria observed was as a result of the partition of synergism between bioactive constituents caused by TLC separation that plays a major role in crude extract and fractions (Eloff et al., 2008). Most of the antibacterial compounds were found in ML5 where the highest numbers of inhibition zones were detected against $S$. aureus and MRSA.

The cells viability at different concentrations of $M$. malabathricum leaves fractions was assessed. The MTT assay was found to have cells viability between 70 and $90 \%$ in all fractions at concentration below $0.063 \mathrm{mg}$ mL $\square 1$ (Fig. 3) while The ML2, ML4 and ML5 of MMML showed increased cell viability of Vero cells of more than $100 \%$ at concentration of $0.0156 \mathrm{mg} \mathrm{mL}^{-1}$. This increase in cell viability at low concentration was worthy to note and may be attributable to its possible mitogenic effect or induction of expression of growth-stimulating constituents evident by an increase in mitochondrial dehydrogenase activity which is in turn estimated by MTT.

The antioxidant activity of $M$. malabathricum leaves has been reported (Zakaria et al., 2011b). The qualitative antioxidant activity of six $M$. malabathricum leaves fractions was evaluated by DPPH and the results showed the presence of constituents with a possible protective effect in preventing cellular damage associated with more than $90 \%$ viability of Vero cells at concentration $0.0156 \mathrm{mg} \mathrm{mL}^{-1}$ for fractions ML1 to ML5. The ML5 fraction showed constituents with antibacterial and antioxidant activities and their $\mathrm{R}_{\mathrm{f}}$ values were 0.33 and 0.4 in CA (Table 3 and 4). Since antioxidant constituents are usually polar substances, it is not surprising that the more polar eluent solvent developed the most antioxidant substances. The presence of two flavonoids with antioxidant activity seems to protect cells from the toxic effect in the ML5 fraction of MMML with cells viability $98.69 \%$ at $0.0156 \mathrm{mg} \mathrm{mL}^{-1}$. Harborne and Williams (2000) reported the importance of two flavonoids: quercetin and kaempferol in the suppression of cytotoxicity of $\mathrm{O}_{2}{ }^{-}$and $\mathrm{H}_{2} \mathrm{O}_{2}$ on Chinese hamster V79 cells in protective manner by their ability to stabilize membranes via decreasing membrane fluidity. In addition, the flavonoids partition in the hydrophobic core of the membrane causes a decrease in lipid fluidity in this region of the membrane (Arora et al., 2000).

\section{CONCLUSION}

The MMML, fractions and two bioactive components exerted potent inhibitory effects against all tested pathogenic bacteria. The M. malabathricum leaves fraction ML5, Kaempferol-3-O-(2",6"-di-O-p-transcoumaroyl)- $\beta$-glucopyranoside and Kaempferol exhibited significantly higher antibacterial activity than was observed against $S$. aureus strain and all tested MRSA. In addition, ML5 had not only the acceptable antibacterial activity with high selectivity index value and low toxicity, it was also found to contain potent antioxidant components with protective role against cellular damage.

\section{ACKNOWLEDGMENT}

The study was supported by Research University Grant provided by Ministry of Higher Education to Universiti Kebangsaan Malaysia (BKBP K006401 and DPP-2013-022).

\section{REFERENCES}

Arora, A., T.M. Byrem, M.G. Nair and G.M. Strasburg, 2000. Modulation of liposomal membrane fluidity by flavonoids and isoflavonoids. Arch. Biochem. Biophys., 373: 102-109. DOI: 10.1006/abbi.1999.1525

Brusotti, G., I. Cesari, A. Dentamaro, G. Caccialanza and G. Massolini, 2013. Isolation and characterization of bioactive compounds from plant resources: The role of analysis in the ethnopharmacological approach. J. Pharmaceutical Biomed. Anal., 7085: 117-119. DOI: 10.1016/j.jpba.2013.03.007

Choudhury, M.D., D. Nath and A.D. Talukdar, 2011. Antimicrobial activity of Melastoma malabathricum L. Biol. Environ. Sci., 7: 76-78.

Cushnie, T.P.T. and A.J. Lamb, 2011. Recent advances in understanding the antibacterial properties of 
flavonoids. Int. J. Antimicrobial Agents, 38: 99-107. DOI: 10.1016/j.ijantimicag.2011.02.014

Das, B.,S. Saha, J. Ferdous, J.M.A. Hannan and S.A.M. Bashar, 2010. OL-029 Antimicrobial activity of tropical plants in the treatment of infectious diseases. Int. J. Infect. Dis., 14: S1-S13. DOI: 10.1016/S1201-9712(10)60037-9

Deby, C. and G. Margotteaux, 1970. Relationship between essential fatty acids and tissue antioxidant levels in mice. C R Seances Soc. Biol. Fil., 164: 2675-2681. PMID: 4258383

Dulger, B. and N. Hacioglu, 2009. antibacterial activity of three endemic hypericum species used in folkloric medicine against methicilin-resistant staphylococcus aureus. Canakkale Onsekiz Mart University.

Eloff, J.N., D.R. Katerere and L.J. McGaw, 2008. The biological activity and chemistry of the southern african combretaceae. J. Ethnopharmacol., 119: 686-699. DOI: 10.1016/j.jep.2008.07.051

Gautam, M.K., M. Gangwar, G. Nath, C.V. Rao, R.K. Goel, 2012. In-vitro antibacterial activity on human pathogens and total phenolic, flavonoid contents of Murraya paniculata Linn. leaves. Asian Pacific J. Tropical Biomed., 2: S1660-S1663. DOI: 10.1016/S2221-1691(12)60472-9

Green, R.J., 2004. Antioxidant activity of peanut plant tissues. Msc., Thesis, North Carolina State University.

Harborne, J.B. and C.A. Williams, 2000. Advances in flavonoid research since 1992. Phytochemistry, 55: 481-504. DOI: 10.1016/S0031-9422(00)00235-1

Joffry, S.M., N.J. Yob, M.S. Rofiee, M.M.R.M.M. Affandi and Z. Suhaili et al., 2012. Melastoma malabathricum (L.) smith ethnomedicinal uses, chemical constituents and pharmacological properties: A review. Evid. Based Complement Alternat. Med., 2012: 48-48. DOI: $10.1155 / 2012 / 258434$

Kalayou, S., M. Haileselassie, G. Gebre-Egziabher S. Sahle and H. Taddele et al. 2012. In-vitro antimicrobial activity screening of some ethnoveterinary medicinal plants traditionally used against mastitis, wound and gastrointestinal tract complication in Tigray Region, Ethiopia. Asian Pacific J. Tropical Biomed., 2: 512-522. DOI: 10.1016/S2221-1691(12)60088-4

Katovai, E., A.L. Burley and M.M. Mayfield, 2012. Understory plant species and functional diversity in the degraded wet tropical forests of Kolombangara
Island, Solomon Islands. Biol. Conservation, 145: 214-224. DOI: 10.1016/j.biocon.2011.11.008

Marzouk, B., Z. Marzouk, R. Decor, L. Mhadhebi and N. Fenina et al., 2010. Antibacterial and antifungal activities of several populations of Tunisian Citrullus colocynthis Schrad. Immature fruits and seeds. J. Mycol. Med., 20: 179-184. DOI: 10.1016/j.mycmed.2010.05.006

Masoko, P. and J.N. Eloff, 2005. The diversity of antifungal compounds of six South African Terminalia species (Combretaceae) determined by bioautography. Afr. J. Biotechnol., 4: 1425-1431.

Nazlina, I., S. Norha, A.W. Zarina and I.B. Ahmad, 2008. Cytotoxicity and antiviral activity of Melastoma malabathricum extracts. Malaysian Applied Biol., 37: 53-55.

NCCLS, 2000. Methods for Dilution Antimicrobial Susceptibility Tests for Bacteria that Grow Aerobically: Approved Standard. 5th Edn., NCCLS, Wayne, ISBN-10: 1562383949, pp: 53.

Nostro, A., M.P. Germano, V. D’Angelo, A. Marino and M.A. Cannatelli, 2000. Extraction methods and bioautography for evaluation of medicinal plant antimicrobial activity. Lett. Applied Microbiol., 30: 379-384. PMID: 10792667

Okusa, P.N., C. Stevigny, M. Devleeschouwer and P. Duez, 2010. Optimization of the culture medium used for direct TLC-bioautography. Application to the detection of antimicrobial compounds from Cordia gilletii De Wild (Boraginaceae). J. Planner Chromatography, 23: 245-249.

Orhan, D.D., B. Ozcelik, S. Ozgen and F. Ergun, 2010. Antibacterial, antifungal and antiviral activities of some flavonoids. Microbiol. Res., 165: 496-504. DOI: 10.1016/j.micres.2009.09.002

Otsuka, N., M.H. Liu, S. Shiota, W. Ogawa and T. Kuroda et al., 2008. Anti-methicillin resistant Staphylococcus aureus (MRSA) compounds isolated from Laurus nobilis. Biol. Pharmaceutical Bull., 31: 1794-1797. PMID: 18758079

Raheel, R., M. Ashraf, S. Ejaz, A. Javeed and I. Altaf, 2013. Assessment of the cytotoxic and anti-viral potential of aqueous extracts from different parts of Acacia nilotica (Linn) Delile against Peste des petits ruminants virus. Environ. Toxicol. Pharmacol., 35: 72-81. DOI: 10.1016/j.etap.2012.11.005

Sgariglia, M.A., J.R. Soberon, D.A. Sampietro, E.N. Quiroga and M.A. Vattuone, 2011. Isolation of antibacterial components from infusion of Caesalpinia paraguariensis bark. A bio-guided 
phytochemical study. Food Chem., 126: 395-404. DOI: $10.1016 /$ j.foodchem.2010.10.104

Sharma, A., V.K. Patel, S. Rawat, P. Ramteke and R. Verma, 2010. Identification of the antibacterial component of some Indian medicinal plants against Klebsiella pneumonia. Int. J. Pharmacy Pharmaceutical Sci., 2: 123-127.

Sirat, H.M., D. Susanti, F. Ahmad, H. Takayama and M. Kitajima, 2010. Amides, triterpene and flavonoids from the leaves of Melastoma malabathricum L. J. Nat. Med., 64: 492-495. DOI: 10.1007/s11418-0100431-8

Suhartono, E., E. Viani, M.A. Rahmadhan, I.S. Gultom and M.F. Rakhman et al., 2012. Screening of medicinal plant for total flavonoid and antioxidant activity in south kalimantan of Indonesian. Int. J. Chem. Eng. Appli., 3: 297-299. DOI: 10.7763/IJCEA.2012.V3.203

Suleiman, M.M., L.J. McGaw, V. Naidoo and J.N. Eloff, 2010. Detection of antimicrobial compounds by bioautography of different extracts of leaves of selected South African tree species. Afr. J. Traditional Complement. Altern. Med., 7: 64-78. PMCID: PMC3005382

Sunilson, J.A.J., K. Anandarajagopal, A.V.A.G. Kumari and S. Mohan, 2008. Antidiarrhoeal Activity of Leaves of Melastoma malabathricum Linn. Ind. J. Pharm. Sci., 71: 691-695. DOI: 10.4103/0250474X.59556
Verma, A.R., M. Vijayakuma, C.V. Rao and C.S. Mathela, 2010. In vitro and in vivo antioxidant properties and DNA damage protective activity of green fruit of Ficus glomerata. Food Chem. Toxicol., 48: 704-709. DOI: 10.1016/j.fct.2009.11.052

Zakaria, Z.A., M.S. Rofiee, A.M. Mohamed, L.K. Teh and M.Z. Salleh, 2011a. In Vitro antiproliferative and antioxidant activities and total phenolic contents of the extracts of Melastoma malabathricum leaves. J. Acupunct. Meridian Stud., 4: 248-256. DOI: 10.1016/j.jams.2011.09.016

Zakaria, Z.A., R.N.S.R.M. Nor, G.H. Kumar, Z.D.F.A. Ghani and M.R. Sulaiman et al., $2011 \mathrm{~b}$. Antinociceptive, anti-inflammatory and antipyretic properties of Melastoma malabathricum leaves aqueous extract in experimental animals. Can. J. Physiol. Pharmacol., 84: 1291-1299. PMID: 17487238 